\title{
Analisis Akurasi Sistem Sensor DHT22 berbasis Arduino terhadap Thermohygrometer Standar
}

\author{
Fitri Puspasari*, Trias Prima Satya, Unan Yusmaniar Oktiawati, Imam Fahrurrozi, dan Hristina Prisyanti \\ Departemen Teknik Elektro dan Informatika, Sekolah Vokasi, Universitas Gadjah Mada, Jl. \\ Yacaranda, Caturtunggal, Kec. Depok, Kabupaten Sleman, Daerah Istimewa Yogyakarta 55281

\section{Intisari}

\begin{abstract}
Telah dilakukan penelitian tentang uji perbandingan suhu dan kelembaban udara menggunakan alat sensor DHT22 berbasis arduino dengan thermohygrometer. Penelitian ini meninjau dari perkembangan teknologi yang semakin berkembang untuk memudahkan pengukuran suhu dan kelembaban menggunakan sensor DHT22 berbasis Arduino. Tujuan dari penelitian ini untuk mengetahui kinerja sensor dan membandingkan hasil pengukuran antara sensor DHT22 dan thermohygrometer. Metode penelitian yang digunakan yaitu metode perbandingan langsung ntara sensor DHT22 dan thermohygrometer standar. Percobaan ini dilakukan dengan metode repeatability sebanyak 5 kali pada masing-masing variasi suhu ruangan. Perbandingan hasil nilai kesalahan rata-rata pada pengukuran suhu dan kelembaban antara sensor DHT22 dengan Thermohygrometer standar menghasilkan nilai 2,99\% untuk kelembaban dan $-2,31 \%$ untuk suhu. Berdasarkan hasil tersebut dapat disimpulkan akurasi dikatakan baik dan dapat diterima karena sesuai dengan data sheet sensor DHT22 yaitu kelembaban yang terukur harus memiliki range antara $2-5 \%$ dan $\pm 5^{\circ} \mathrm{C}$ untuk nilai suhu.
\end{abstract}

\begin{abstract}
Research has been carried out on a comparison test of temperature and humidity using an arduino-based DHT22 sensor with a thermohygrometer. This study reviews developments in technology that is increasingly developing to facilitate the measurement of temperature and humidity using Arduino-based DHT22 sensors. The purpose of this study was to determine the sensor performance and compare the measurement results between the DHT22 sensor and the thermohygrometer. The research method used is the direct comparison method between DHT22 sensor and standard thermohygrometer. This experiment was conducted with a repeatability method of 5 times at each room temperature variation. Comparison of the results of the average error value in the measurement of temperature and humidity between the DHT22 sensor with a standard Thermohygrometer produces a value of $2.99 \%$ for humidity and $-2.31 \%$ for temperature. Based on these results it can be concluded that the accuracy is said to be good and acceptable because it matches the DHT22 sensor datasheet ie the measured humidity must have a range between $2-5 \%$ and $\pm 5^{\circ} \mathrm{C}$ for the temperature value.
\end{abstract}

Keywords: arduino; DHT22; humidity; temperature; thermohygrometer.

*Corresponding author: fitri.puspasari@ugm.ac.id

http://dx.doi.org/10.12962/j24604682.v16i1.5717

2460-4682 @DDepartemen Fisika, FSAD-ITS

\section{PENDAHULUAN}

Pengukuran suhu dan kelembaban ruangan pada umumnya dilakukan dengan menggunakan thermohygrometer. Thermohygrometer merupakan alat yang dapat digunakan untuk mengukur dua buah besaran fisis yaitu termometer dan hygrometer.

Termometer biasa digunakan dalam pemantauan suhu, sedangkan hygrometer memiliki kegunaan sebagai pengukur kelembaban. Terdapat banyak sekali jenis sensor yang dapat digunakan untuk melakukan pengukuran suhu dan kelembaban salah satunya adalah DHT22.

DHT22 (Gambar 1) adalah sensor digital kelembaban dan suhu relatif. Sensor DHT22 menggunakan kapasitor dan termistor untuk mengukur udara disekitarnya dan keluar sinyal pada pin data. DHT22 diklaim memiliki kualitas pembacaan yang baik, dinilai dari respon proses akuisisi data yang cepat dan ukurannya yang minimalis, serta dengan harga relatif murah jika dibandingkan dengan alat thermohygrometer [1].

Beberapa penelitian yang mengimplementasikan sensor suhu dan kelembaban diantaranya adalah pengukuran suhu dan kelembaban dengan menggunakan sensor DHT22 berbasis menggunakan mikrokontroler ATmega $16 U 2$ [2], Pemanfaatan sensor DHT22 dalam implementasi sistem kontrol ruangan dalam suatu bangunan [3], aplikasi sensor DHT22 dalam rumah kaca [4], pembuatan desain sistem kontrol dan monitoring suhu dan kelembaban berbasis mikrokontroler dengan sensor DHT11 [5], pembuatan aplikasi jaringan sensor nirkabel untuk monitoring gas karbon monoksida dengan sensor HSM 20-G [6], pembuatan sistem pemantauan suhu dan 


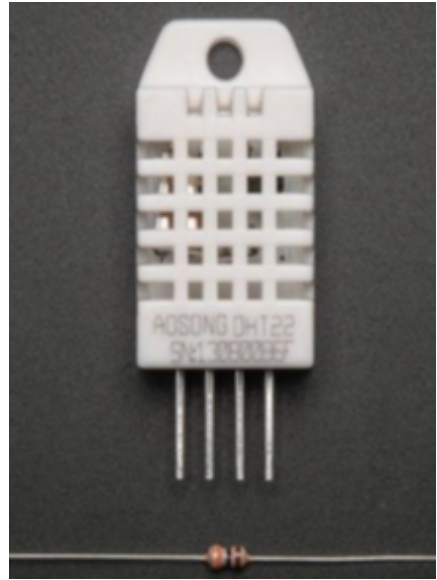

Gambar 1: Sensor DHT22 [1].

kelembaban pada pertumbuhan tanaman menggunakan sensor DHT22 [7], pembuatan sistem pengontrol kecepatan kipas secara otomatis menggunakan sensor DHT22 [8], pemanfaatan sensor DHT11 pada pembuatan sistem pengaman ruangan [9].

Sensor DHT22 sangat mudah diaplikasikan pada mikrokontroller tipe Arduino karena memiliki tingkat stabilitas yang dapat dipercaya dan fitur kalibrasi yang memiliki hasil sangat akurat. Salah satu jenis arduino adalah Arduino Uno. Arduino Uno merupakan papan minimum sistem mikrokontroler yang memiliki sifat pen source. Selain itu arduino memiliki keistimewaan tersendiri dibanding dengan board mikrokontroler yang lain, Arduino telah menggunakan bahasa pemrograman yang dibuat menggunakan perangkat lunak [5].

Selain itu didalam board arduino memiliki loader dalam bentuk USB sehingga memudahkan dalam membuat program mikrokontroller didalam arduino. Beberapa penelitian terkait yang menggunakan Arduino Uno adalah pembuatan rancangan pengukur suhu dan kelembaban dengan menggunakan Arduino dan DHT11 [10], dan pembuatan sistem smart farming berbasis arduino dan sensor DHT11 [11].

Pada penelitian ini memanfaatkan sensor DHT22, dimana dari beberapa hasil penelitian sensor DHT22 diklaim memiliki nilai akurasi hasil lebih baik dibandingkan dengan sensor sejenisnya yaitu DHT11. Penelitan tersebut diantaranya pengujian kualitas pada empat sensor suhu udara yaitu, LM35, DHT11, DHT22, dan DS18B20. Hasil pengujian menunjukkan bahwa eror pengukuran LM35, DHT11, DHT22, DS18B20 berturut-turut adalah sebesar 4,69\%, 3,12\%, 1,96\%, $1,6 \%$ [12].

Penelitian terkait lainnya ialah membandingkan nilai akurasi sensor DHT11 terhadap DHT22 pada pengukuran suhu dan kelembaban saat digunakan baik di dalam maupun di luar ruangan. Variasi dari pengujian ini adalah dengan menggunakan platform ATMEL AVR dan Arduino. Hasil dari pengujian yang telah dilakukan, DHT22 memiliki akurasi dengan galat relatif pengukuran suhu $4 \%$ dan kelembaban $18 \%$. Sedangkan DHT11 memiliki rentang galat yang lebih besar yaitu $1-7 \%$ untuk pengukuran suhu dan $11-35 \%$ untuk kelembaban [13]. Penelitian-penelitian tersebut membandingkan ni-

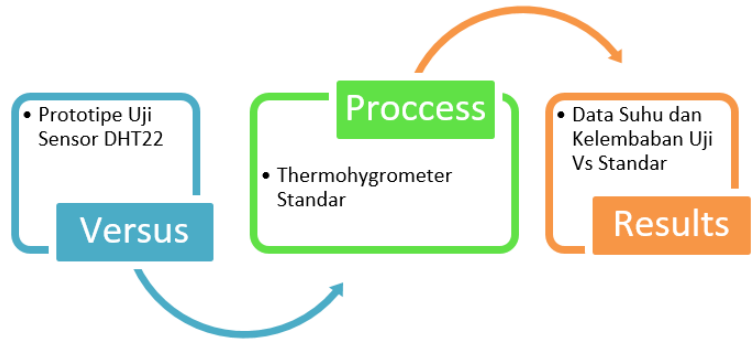

Gambar 2: Diagram blok penelitian.

lai akurasi antar sensor. Sedangkan akan lebih baik jika ditambahkan dengan pembanding berupa alat yang standar yang memiliki sertifikat kalibrasi.

Penelitian terkait diantaranya perancangan sistem pemantauan hasil pengukuran ini ditunjang oleh perancangan dua purwarupa pengukur suhu dan kelembaban menggunakan sensor DHT22 yang kemudian diuji secara bersamaan dengan dipantau oleh alat standar. Hasil dari penelitian tersebut sistem yang dibuat mampu mengukur suhu dari $-40^{\circ} \mathrm{C}$ sampai $80^{\circ} \mathrm{C}$ dengan ketelitian $\pm 0,1^{\circ} \mathrm{C}$ dan kelembaban dari $0 \%$ sampai $100 \%$ dengan ketelitian $\pm 5 \%$ [14].

Pengembangan suatu thermohygrometer digital juga telah dibuat dengan sistem pengendali berupa platorm Arduino, DHT22 serta modul FTDI232RL. Hasil penelitian tersebut menunjukkan nilai rerata ketidakpastian pengukuran untuk suhu sebesar 6\% dan kelembaban 19\%. Sedangkan rata-rata selisih pengukuran thermohygrometer digital dengan thermohygrometer acuan untuk suhu adalah $1,7^{\circ} \mathrm{CC}$ dan kelembaban $10,2 \%$ [15].

Berdasarkan uraian di atas, penulis melakukan penelitian dengan tujuan untuk merancang sebuah alat berupa alat pengukur suhu dan kelembaban udara menggunakan sensor DHT22 berbasis mikrokontroler berupa arduino uno yang dilengkapi dengan LCD $(16 \times 2) \mathrm{cm}^{2}$ dan kemudian dianalisis datanya dengan mengacu pada sebuah alat ukur suhu digital standar berupa thermohygrometer.

\section{METODE PENELITIAN}

Metodologi yang digunakan dalam penelitian ini, terdiri dari perancangan perangkat keras dan perancangan perangkat lunak. Perancangan perangkat keras adalah sebagai implementasi dari sensor suhu yang dirancang. Perancangan perangkat keras diawali dengan merancang instrumen sensor DHT22 dan thermohygrometer pada perangkat lunak Proteus 8.6. Rangkaian skematik dengan program arduino yang sudah dicek dan dijalankan, maka dilanjutkan dengan merakit alat thermohygrometer pada skematik ke arduino kit dan menghubungkannya ke PC.

Perancangan perangkat lunak adalah bagaimana sistem pada sensor suhu DHT22 berbasis arduino ini dapat bekerja. Kemudian dibandingkan dengan alat thermohygrometer sebagaimana digambarkan dalam diagram blok (Gambar 2). Dalam penelitian ini digunakan Arduino Uno, perangkat 


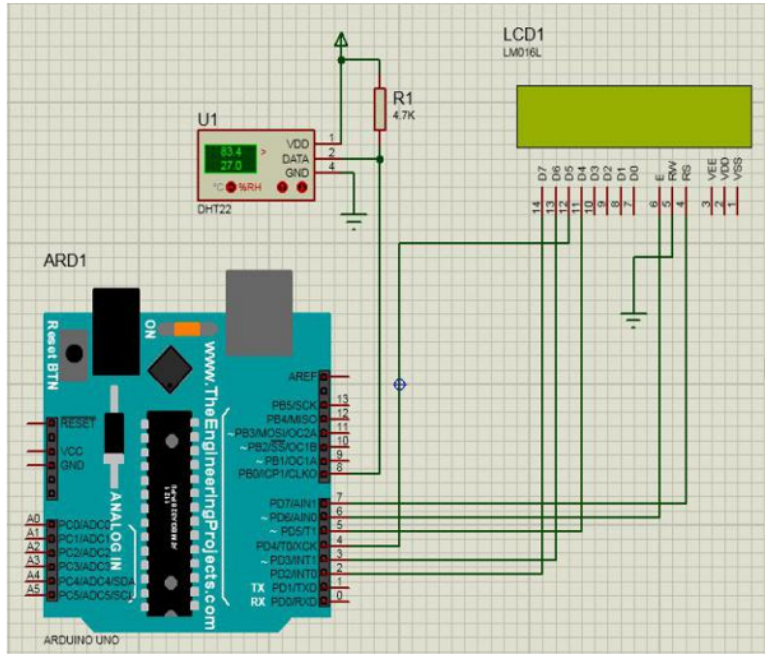

Gambar 3: Skematik pada perangkat lunak Proteus.

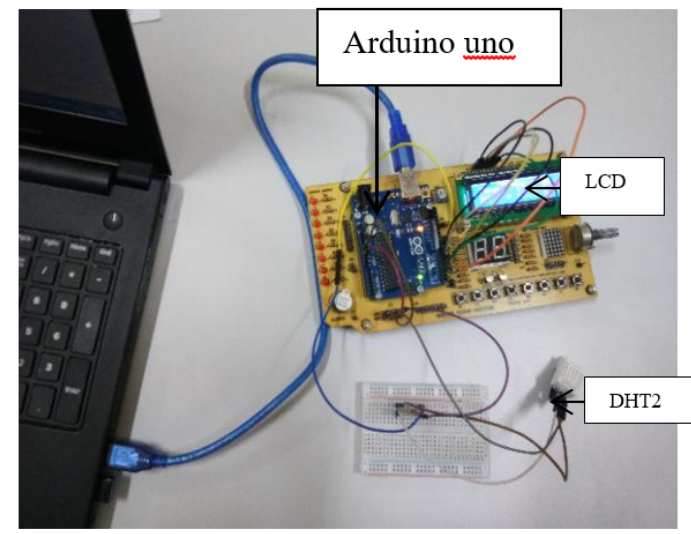

Gambar 4: Rangkaian perangkat keras.

lunak Arduino Uno, perangkat lunak Proteus 8 Pro, project board, jumper, resistor $10.000 \Omega$, sensor DHT22 dan thermohygrometer sebagai alat pengukur besar suhu dan kelembaban standar. Pengimplementasian sistem yang dirancang, ditunjukkan pada Gambar 3 dan Gambar 4.

Proses akuisisi data pada arduino seperti alur diagram pada Gambar 5. Pengujian sensor DHT22 dan Arduino yang sudah dirangkai di atas breadboard dihubungkan dengan laptop. Data suhu dan kelembaban tampil di serial monitor perangkat lunak Arduino IDE dan LCD. Komunikasi yang digunakan menggunakan komunikasi serial.

Dalam pengukuran suhu dan kelembaban udara ini, untuk mengetahui perbandingan antara alat uji dan alat standar, dapat dilakukan perhitungan yang dituliskan secara sistematis sebagai berikut:

- Rata-rata

$$
\bar{x}=\frac{x_{1}+x_{2}+x_{3}+\cdots+x_{n}}{n}
$$

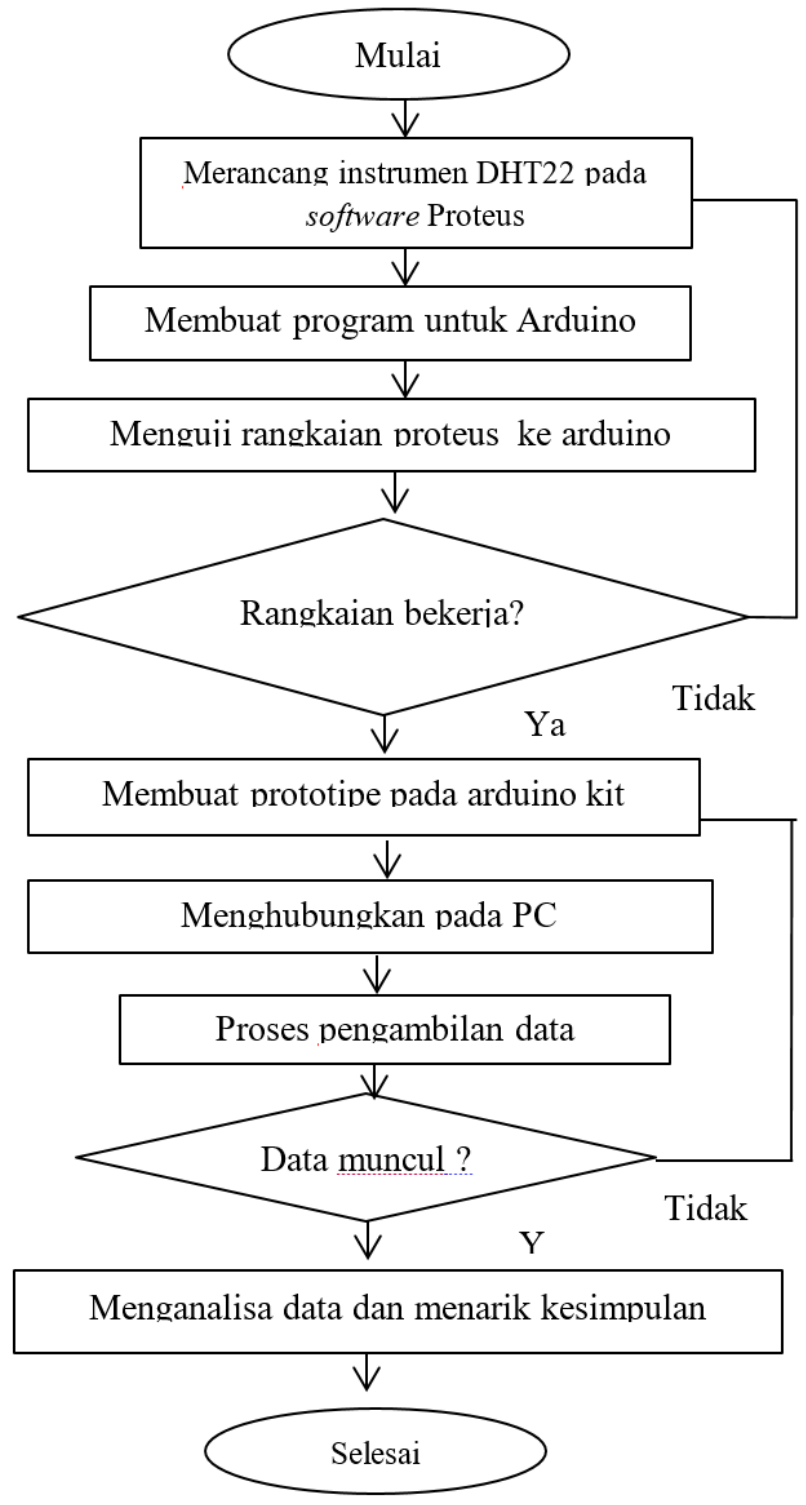

Gambar 5: Tahapan penelitian.

- Standar deviasi

$$
S D=\sqrt{\frac{\Sigma\left(\bar{x}-x_{i}\right)^{2}}{n-1}}
$$

- Nilai Error

$$
\text { Error }=\mid \text { nilai uji }- \text { nilai standar } \mid
$$

- Ketidakpaastian relatif

$$
K R=\frac{\text { uji standar }}{\text { standar }} \times 100 \%
$$

dengan $\bar{x}$ adalah nilai rata-rata, $x_{1}+x_{2}+x_{3}+\cdots+x_{n}$ adalah data ke-n, $U j i$ adalah nilai pembacaan pada alat uji, standar adalah nilai pembacaan pada alat standar. 


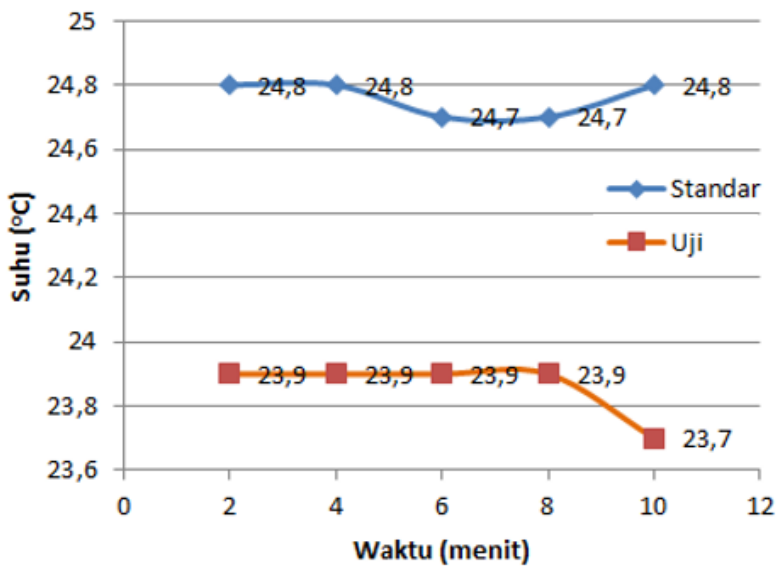

(a) Suhu

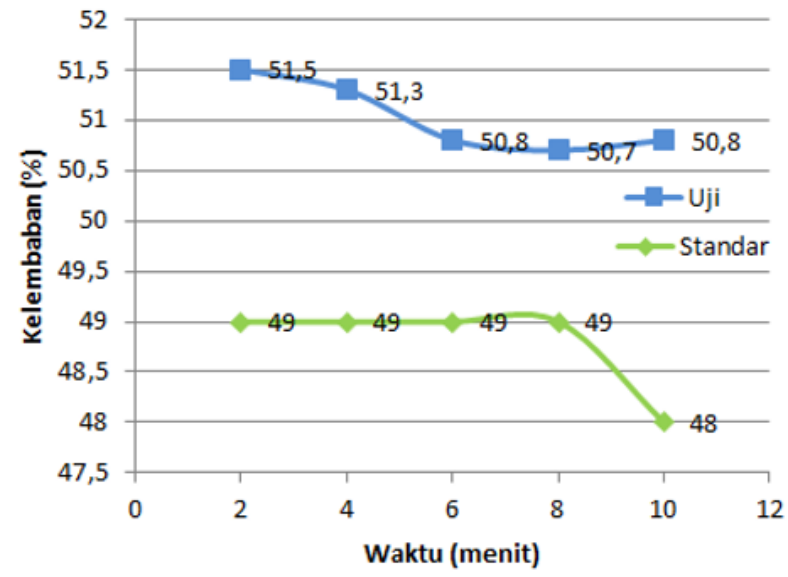

(b) Kelembaban

Gambar 6: Grafik perbandingan pengukuran (a). suhu, (b). kelembaban terhadap waktu pada suhu $28^{\circ} \mathrm{C}$.

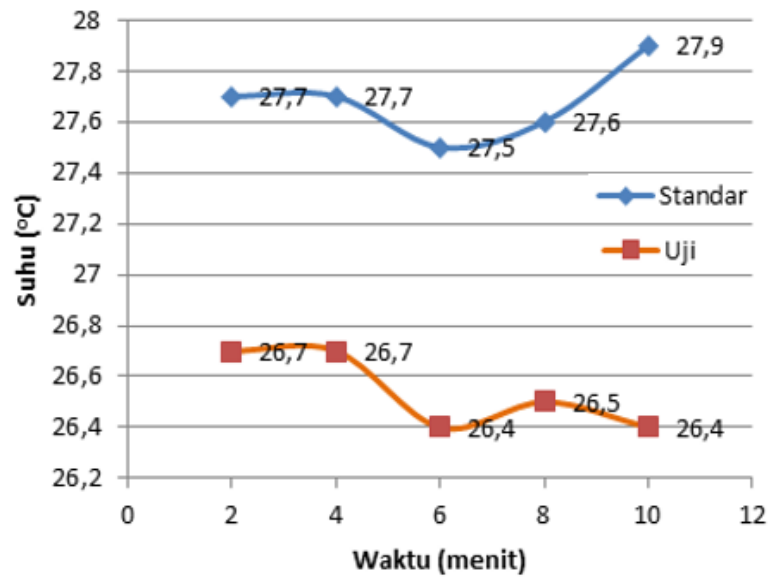

(a) Suhu

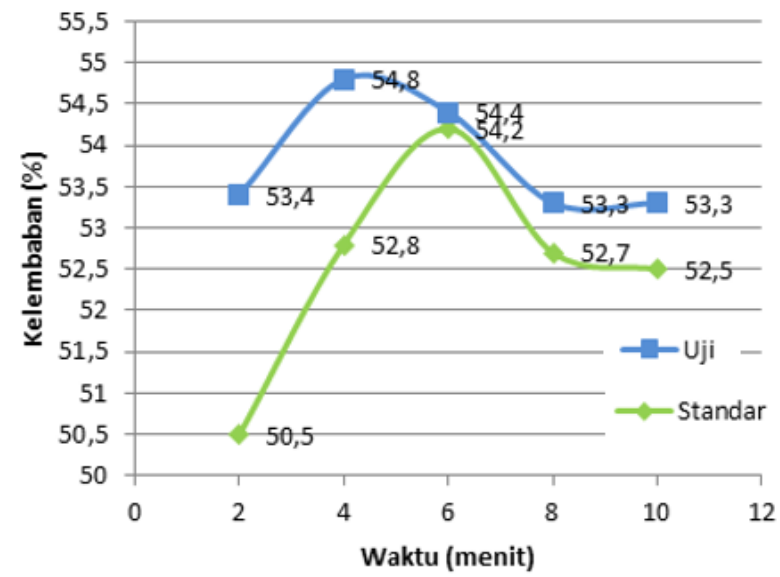

(b) Kelembaban

Gambar 7: Grafik perbandingan pengukuran (a). suhu, (b). kelembaban terhadap waktu pada suhu $23^{\circ} \mathrm{C}$.

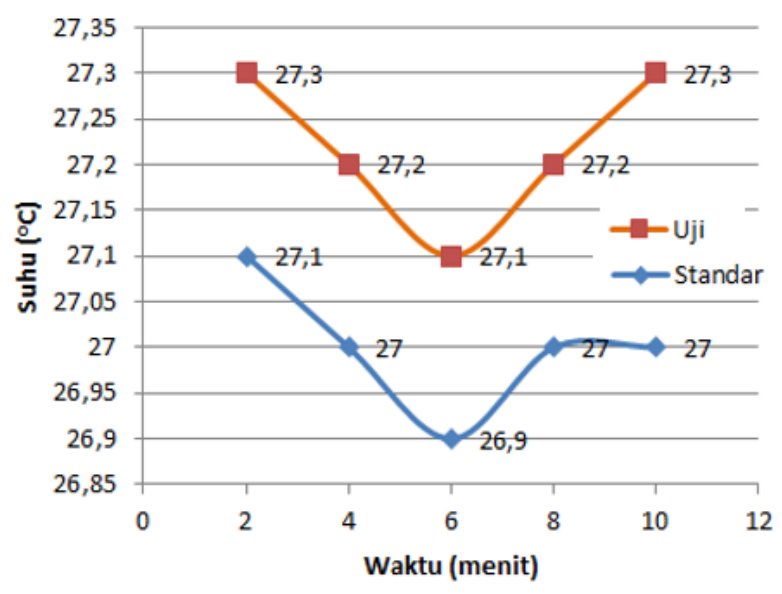

(a) Suhu

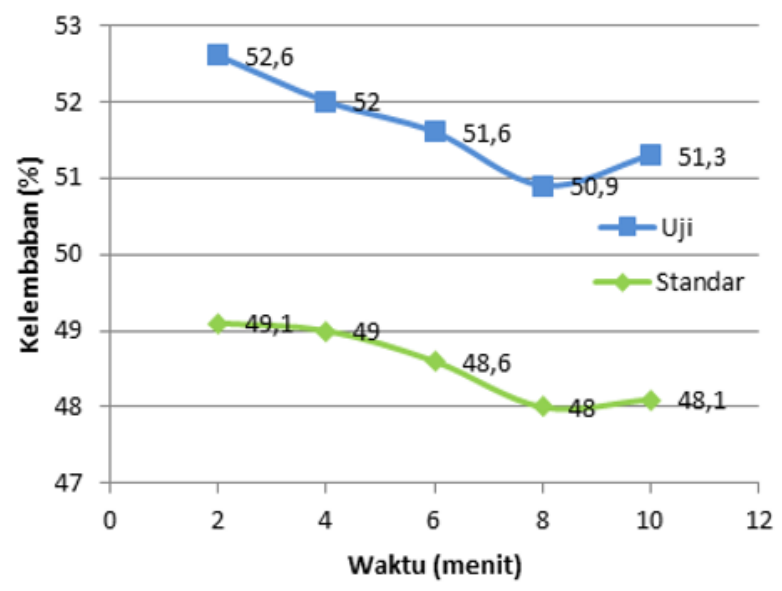

(b) Kelembaban

Gambar 8: Grafik perbandingan pengukuran (a). suhu, (b). kelembaban terhadap waktu pada suhu $18^{\circ} \mathrm{C}$. 


\section{HASIL DAN PEMBAHASAN}

Dari hasil percobaan pengukuran suhu dan kelembaban udara pada tiga kondisi suhu AC ruangan yang berbeda yakni pada suhu 28,23 , dan $18^{\circ} \mathrm{C}$. Pengambilan data dilakukan secara bersamaan dengan 2 alat ukur yaitu thermohygrometer dan alat uji berupa prototipe sensor suhu DHT22. Pengambilan dilakukan setiap 5 detik selama 2 menit pertama dan dilakukan pengulangan sebanyak 5 kali pada menit selanjutnya yaitu menit ke 4,6,8, dan 10. Data yang disajikan dalam grafik adalah data rata-rata setiap pengulangan. Data yang didapatkan diolah untuk mencari error pada pengukuran tersebut. Hasil yang didapatkan dari pengukuran ditunjukkan dalam Gambar 6, 7, dan 8.

Grafik perbandingan pengukuran suhu $\left({ }^{\circ} \mathrm{C}\right)$ dan kelembaban (\%) terhadap waktu menggunakan thermohygrometer standar dan sensor DHT22 ditunjukkan pada Gambar 6, 7, dan 8. Garis biru merupakan hasil suhu yang diukur menggunakan sensor DHT22 sedangkan garis orange (hasil data suhu) dan garis hijau (hasil data kelembaban) merupakan hasil yang diukur menggunakan thermohygrometer standar.

Perbedaan suhu dari variasi AC memiliki perbedaan dengan hasil yang terukur pada sensor uji maupun alat standar, hal ini dikarenakan pengaruh kondisi ruang laboratorium dan jarak posisi antara AC dengan alat uji maupun standar yang berjauhan. Sehingga menimbulkan selisih hasil suhu terukur. Berdasarkan Gambar 6 dan 7, data pengukuran suhu cenderung konstan baik pada alat standar maupun uji. Sedangkan untuk data pengukuran kelembaban nilai cenderung konstan ditunjukkan Gambar 6 dan 8.

Pada variasi suhu pertama pada thermohygrometer standar diperoleh nilai kelembaban dan suhu udara pada alat thermohyrometer standar dan uji berurutan adalah $(48,8 \pm 0,4) \%$ dan $(51,0 \pm 0,4) \%$ sedangkan suhunya adalah $(24,80 \pm 0,05){ }^{\circ} \mathrm{C}$ dan $(23,90 \pm 0,09)^{\circ} \mathrm{C}$. Nilai error (selisih) kelembaban sebesar $2,2 \%$ dan suhu $-0,9^{\circ} \mathrm{C}$.

Pada variasi suhu kedua, diperoleh nilai kelembaban dan suhu pada alat thermohygrometer standar dan uji secara beru- rutan adalah $(52,0 \pm 1,3) \%$ dan $(53,8 \pm 0,7) \%$ sedangkan suhunya adalah $(27,7 \pm 0,2)^{\circ} \mathrm{C}$ dan $(26,9 \pm 0,2)^{\circ} \mathrm{C}$. Dengan nilai error kelembaban sebesar $1,3 \%$ dan suhu $-1,1^{\circ} \mathrm{C}$.

Pada variasi suhu ketiga diperoleh nilai kelembaban dan suhu pada thermohygrometer standar dan uji secara berurutan adalah $(48,6 \pm 0,5) \%$ dan $(51,7 \pm 0,7) \%$ sedangkan suhunya adalah $(27,00 \pm 0,07)^{\circ} \mathrm{C}$ dan $(27,2 \pm 0,08) \mathrm{C}$. Dengan nilai error kelembaban sebesar $3,1 \%$ dan suhu $0,2^{\circ} \mathrm{C}$.

Berdasarkan hasil perhitungan dan pengujian, suhu dan kelembaban sensor DHT22 di atas menunjukkan kualitas hasil yang baik karena sesuai dengan data sheet sensor bahwa kelembaban yang terukur harus memiliki rentang antara $2 \%$ $5 \%$, sebagaimana juga ditunjukkan oleh referensi pada penelitian sebelumnya yaitu nilai akurasi sebesar $2 \%$ untuk nilai kelembaban dan $0,5^{\circ} \mathrm{C}$ untuk suhu [2]. Perhitungan nilai error rata-rata berdasarkan rata-rata jumlah error hasil pengukuran antara sensor DHT22 dengan thermohygrometer standar menghasilkan nilai 2,99\% untuk kelembaban dan $-2,31 \%$ untuk suhu.

\section{SIMPULAN}

Perbandingan hasil nilai kesalahan rata-rata pada pengukuran suhu dan kelembaban antara sensor DHT22 dengan thermohygrometer standar menghasilkan nilai 2,99\% untuk kelembaban dan $-2,31 \%$ untuk suhu. Dari pembahasan di atas dapat disimpulkan bahwa selisih penunjukan nilai suhu dan kelembaban pada sensor DHT22 sesuai dengan data sheet sensor DHT22 yaitu kelembaban yang terukur harus memiliki range antara $2 \%-5 \%$ dan $\pm 5^{\circ} \mathrm{C}$ untuk nilai suhu.

\section{Ucapan Terima Kasih}

Ucapan terima kasih kepada pihak Direktorat Penelitian UGM yang secara langsung memberikan kontribusi pada artikel yang ditulis, berupa bantuan dana penelitian (3943/UN1/DITLIT/DIT-LIT/LT/2019).
[1] L. Abdulrazzak, I.A. Bierk, H. Aday, "Humidity and temperature monitoring", Int. J. Eng. Technol., vol. 7, no. 4, pp. 51745177,2018

[2] M. Bogdan, "How to Use the DHT22 Sensor for Measuring Temperature and Humidity with the Arduino Board", ACTA Univ. Cibiniensis, vol. 68, no. 1, pp. 22-25, 2016.

[3] I. Lita, D.A. Visan, I.B. Cioc, A.G. Mazare, and R.M. Teodorescu, "Indoor environmental parameters monitoring for building automation systems", Proc. 8th Int. Conf. Electron. Comput. Artif. Intell. ECAI 2016, vol. 8, pp. 41-44, 2016.

[4] N. Hassan, S.I. Abdullah, A.S. Noor, and M. Alam, "An automatic monitoring and control system inside greenhouse", 2015 Int. Conf. Green Energy Technol. ICGET, 2015, pp. 1-5, 2015

[5] Y. Zhou, Q. Zhou, Q. Kong, and W. Cai, "Wireless temperature \& humidity monitor and control system", 2012 2nd Int. Conf. Consum. Electron. Commun. Networks, CECNet 2012 - Proc., pp. 2246-2250, 2012.

[6] Firdaus, N. Ahriman, A. Yulianto, and M. Kusriyanto, "Wire- less sensor network application for carbon monoxide monitoring”, Proceeding 2015 9th Int. Conf. Telecommun. Syst. Serv. Appl. TSSA 2015, pp. 1-4, 2015.

[7] C.G. Priya, M. Abishek Pandu, and B. Chandra, "Automatic plant monitoring and controlling system over GSM using sensors", Proc. - 2017 IEEE Technol. Innov. ICT Agric. Rural Dev. TIAR 2017, pp. 173-176, 2017.

[8] S. Kaushik, Y.S. Chouhan, N. Sharma, and S. Singh, "Automatic Fan Speed Control using Temperature and Humidity Sensor and Arduino", Int. J. Adv. Res., vol. 4, no. 2, pp. 453-457, 2018.

[9] Y. Siswanto, Anif, M., Hayati, D.N., "Pengamanan Pintu Ruangan Menggunakan Arduino Mega 2560, MQ-2, DHT-11 Berbasis Android", Rekayasa Sist. dan Teknol. Inf., vol. 3, no. 1, pp. 66-72, 2019.

[10] D. Srivastava, A. Kesarwani, and S. Dubey, "Measurement of Temperature and Humidity by using Arduino Tool and DHT11”, Int. Res. J. Eng. Technol., vol. 05, no. 12, pp. 876- 
878, 2018.

[11] M.K. Anushree and R. Krishna, "A smart farming system using Arduino based technology", Int. J. Adv. Res. Ideas Innov. Technol., vol. 4, no. 4, pp. 850-856, 2018.

[12] K.Y.A. Utama, "Perbandingan Kualitas Antar Sensor Suhu dengan Menggunakan Arduino Pro Mini”, e-NARODROID, vol. 2, no. 2, pp. 145-150, 2016.

[13] S.A.H. Saptadi, "Perbandingan Akurasi Pengukuran Suhu dan Kelembaban Antara Sensor DHT11 dan DHT22", J. INFOTEL - Inform. Telekomun. Elektron., vol. 6, no. 2, pp. 49-56, 2014.
[14] S.I. Jumaila and S. Maulida, "Pemantauan Suhu dan Kelembaban di Laboratorium Kalibrasi Tekanan dan Volume Berbasis Web Secara Real Time", J. Otomasi Kontrol dan Instrumentasi, vol. 9, no. 1, pp. 9-19, 2017.

[15] S.A.H. Saptadi, D. Kurnianto, "Rancang Bangun Thermohygrometer Digital Menggunakan Sistem Mikropengendali Arduino Dan Sensor DHT22”, Pros. SNST Ke-6 Tahun 2015, pp. 84-88, 2015. 